7 World Health Organization, Working Group on Ischaemic Heart Disease Registers. W.H.O., Regional Office for Europe, Copenhagen, 1971. 8 Pike, M. C., and Morrow, R. H., British fournal of Preventive and Social Medicine, 1970, 24, 42.

9 Miettinen, O. S., Biometrics, 1970, 26, 75.

10 Goldbourt, U., and Medalie, J. H., British fournal of Preventive and Social Medicine, 1974, 28, 116.

11 Mann, J. I., and Thorogood, M., British Heart fournal. In press.

12 Kay, C. R., Smith, A., and Richard, S., Lancet, 1969, 2, 1228.

13 Kay, C. R., Smith, A., and Richard, S., Lancet, 1969, 2, 1228.

14 Vessey, M. P., et al., International fournal of Epid

14 Stokes, S., and Wynn, V., Lancet, 1971, 2, 677.

16 Mulcahy, R., Hickey, N., and Maurer, B., Circulation, 1967, 36, 577.
17 Oliver, M. F., British Medical fournal, 1970, 2, 210.

18 Oliver, M. F., British Medical Fournal, 1974, 4, 253

19 Inter-Society Commission for Heart Disease Resources, Circulation, 1970, 42, A55.

${ }^{20}$ Mann, J. I., and Inman, W. H. W., British Medical Fournal, 1975, 2, 245. 21 Bone, M., Family Planning Services in England and Wales. London, H.M.S.O., 1973.

22 Bone, M., personal communication, 1973.

23 Inman, W. H. W., et al., British Medical fournal, 1970, 2, 203.

24 Inman, W. H. W., and Vessey, M. P., British Medical fournal, 1968, 2, 193.

25 Vessey, M. P., and Doll, R., British Medical fournal, 1968, 2, 199

26 Beaumont, J. L., et al., Bulletin of the World Health Organization, 1970, 43891 .

\title{
Oral Contraceptives and Death from Myocardial Infarction
}

\author{
J. I. MANN, W. H. W. INMAN
}

British Medical fournal, 1975, 2, 245-248

had been coded to rubric 410 according to the eighth revision of the International Classification of Diseases (myocardial infarction and synonymous terms) were obtained from the Registrar General. A total of 726 were received. All deaths in women under the age of $\mathbf{4 0}$

\section{Summary}

We investigated 219 deaths from myocardial infarction in women under the age of 50 . Their histories were compared with those of living age-matched controls selected from the same general practices. The frequency of use of oral contraceptives during the month before death was significantly greater in the group with infarction than during the corresponding month in the control group and the average duration of use was longer. No information on cigarette smoking was available but the proportion of women being treated for hypertension or diabetes was greater among those who died than among the controls. This did not alter the overall conclusion that the risk of fatal myocardial infarction was greater in the women using oral contraceptives, particularly in the older age groups.

\section{Introduction}

Inman and Vessey's report to the Committee on Safety of Drugs on deaths from pulmonary embolism and coronary and cerebral thrombosis in women of childbearing age was published in $1968 .{ }^{1}$ In the cases of pulmonary embolism and cerebral thrombosis a strong relationship was found with the use of oral contraceptives when these disorders occurred in the absence of predisposing conditions. More of the women who died from coronary thrombosis in the absence of predisposing conditions had also been using oral contraceptives than would have been expected from the experience of the control group, but for this condition the difference was not quite significant and a definite association was considered not proved. Later studies $^{2}{ }^{3}$ were not conclusive and we thought it desirable to undertake a further investigation of deaths from myocardial infarction in 1973.

\section{Selection of Cases}

Transcripts of all death certificates relating to women under the age of 50 years who died in England and Wales during 1973 and which

\section{University of Oxford, OX1 3QN}

J. I. MANN, M.B., PH.D., Lecturer in Social and Community Medicine

Committee on Safety of Medicines, London EC2A 1PP

W. H. W. INMAN, M.R.C.P., M.F.C.M., Principal Medical Officer years, every second death in the 40-44-year age group, and every fifth death in the 45-49-year age group were selected for the study, giving a total of 277 cases (table I). Selection was made consecutively as batches of certificates were received.

TABLE I-Numbers of Death Certificates Received, Selected for Study, Investigated, and Included in Present Analysis

\begin{tabular}{|c|c|c|c|c|}
\hline Age group (years): & $<40$ & $40-44$ & $45-49$ & Total \\
\hline 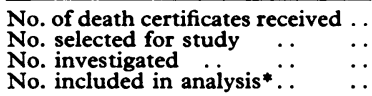 & $\begin{array}{l}86 \\
86 \\
73 \\
51(81)\end{array}$ & $\begin{array}{l}192 \\
100 \\
79 \\
54(56)\end{array}$ & $\begin{array}{l}448 \\
91 \\
67 \\
48(59)\end{array}$ & $\begin{array}{l}726 \\
277 \\
219 \\
153(196)\end{array}$ \\
\hline
\end{tabular}

- Numbers of control patients are given in parentheses.

Efforts were made to interview the general practitioners who had cared for the patients. In 15 cases either the women were not registered with any doctor or the coroner, hospital, or local executive council could not identify him, and the medical records of nine women had been lost and no other data source was available. A further 34 deaths were not investigated because the general practitioner could not be interviewed. Thus $58(21 \%)$ of the 277 deaths could not be studied.

The remaining 219 deaths were investigated by the committee's medical field officers, as a result of which a further 66 cases were excluded. In 37 cases evidence for the diagnosis of myocardial infarction was thought to be inadequate. Deaths were included in the final analysis only when the diagnosis was substantiated by necropsy findings or a history of typical chest pain together with electrocardiographic or enzymatic confirmation as defined by the World Health Organization. ${ }^{4}$ In 23 cases $(10.5 \%)$ a necropsy carried out after the death certificate had been completed or (less often) other evidence suggested that death was attributable to a different cause. A further six cases were excluded because the wrong sex, age, or year of death had been given on the certificate. The remaining 153 deaths provide the basis for this report. In 104 cases the diagnosis was substantiated at necropsy.

\section{Procedure}

Forty-eight members of the committee's staff of medical officers took part in the field work. During the investigation of each death one of them completed a questionnaire as fully as possible with the aid of the general practitioner and any other doctors who had attended the patient during her terminal illness. Since the general practitioner's records had usually been returned to the local executive council after the patient's death he was asked to retrieve them before being interviewed. These major sources of information were often supplemented by hospital case notes, family planning clinic records, necropsy reports, and court records supplied by a coroner. 
In addition to providing details of the fatal cases each general practitioner gave information about certain other women in his practice. Initially two living controls matched for five-year age group and marital status were selected for each case being investigated. The general practitioner located in his files the position which would have been occupied by the late patient's records and which was usually still occupied by records relating to other members of her family. Moving first forwards and then backwards from that position the doctor selected the first two sets of case notes relating to women appropriate for age and marital status. Irrespective of whether he had all the necessary information about these patients they were accepted as controls. Similar questionnaires were completed for each control. It soon became apparent, however, that the procedure was making considerable demands on the general practitioners' time, and it was later modified so that two controls were requested only for the patients with myocardial infarction who were under 40 years of age and one for those over 40 . In the cases of 21 of the 51 patients with infarction under 40 the doctor was able to find time to provide information for only one control. Control patients were sought for all 219 cases investigated but the data presented here include only the controls for cases (153) in which the diagnosis had been convincingly substantiated.

Differences between the characteristics of the patients with infarction and the controls were tested by the $\chi^{2}$ test or by Fisher's exact probability test when the numbers were small. When considering the differences in all age groups (tables II and IV) summary $\chi^{2}$ values were calculated by the method of Miettinen. ${ }^{5}$ Individual matching was not taken into account in the statistical evaluation of the results because for some patients certain items of information were not available. The number of patients to whom this applied is given in each of the tables of results.

\section{Results}

The oral contraceptive practice of the patients with infarction and the controls is shown in table II. In each age group the proportion of current users was greater in the patients with infarction. Current use was defined as use in the month before death (in the case of the patients with infarction) or use during the same calendar period for the control patients. The proportions of ex-users (women who had used these preparations at some time in the past but were not current users) were not appreciably different between the two groups. The duration of use by current users is shown in table III. In all age groups the patients with infarction had been using the preparations on average for longer than the control women. This trend was significant at the $5 \%$ level when all age groups were considered together, the $\chi^{2}$ test for trend as described by Armitage ${ }^{6}$ being used. The data were in addition analysed to examine the oestrogen content of the oral contraceptives used, but the use of high-dose oestrogen preparations before 1970 was not more common among the patients with infarction.

Treated hypertension and diabetes were significantly more common in the patients with infarction than in the controls (table IV). Blood pressure and blood glucose levels were not available for most of the patients and controls and the presence of hypertension and diabetes could therefore be defined only on the basis of any form of treatment for these conditions. Our figures are therefore likely to underestimate the prevalence of hypertension and diabetes in both groups. Treated obesity, thyroid disease, renal disease, and pre-eclamptic toxaemia were not reported appreciably more often in the patients with myocardial infarction.

There were no significant differences between the two groups at any age with regard to social class and parity, nor was there an excessive prevalence of premature menopause among the patients with infarction in any age group. (Eight per cent. of all the patients with infarction and $9 \%$ of the control patients were postmenopausal.)

We also tried to determine whether the association between oral contraceptives and myocardial infarction could be explained by an association between these preparations and the other risk factors studied. Only four of the 31 patients with infarction and one of the 19 controls currently using oral contraceptives were also being treated for hypertension or diabetes. Furthermore, when patients who had received any form of treatment for either hypertension or diabetes were excluded from the two groups, $26 \%$ of the remaining patients with infarction and $11 \%$ of the controls were current users $(P<0.01)$. This suggests that oral contraceptives exert an effect which is independent of hypertension and diabetes as defined here. We could not investigate the possible confounding effect of cigarette smoking, since few precise data could be obtained by the method of inquiry used, which stopped short of interrogating relatives.

\section{Discussion}

These results suggest that there is an increased risk of death from myocardial infarction in women using oral contraceptives. The first report to the Committee on Safety of Drugs concerned deaths from myocardial infarction in the 20-44-year age group

TABLe II-Oral Contraceptive Practice of Myocardial Infarction (M.I.) and Control Patients. Percentages are Given in Parentheses

\begin{tabular}{|c|c|c|c|c|c|c|c|c|c|c|c|}
\hline \multirow{3}{*}{\multicolumn{4}{|c|}{ Oral Contraceptive Practice }} & \multicolumn{6}{|c|}{ Age Group of Women (Years) } & & \\
\hline & & & & \multicolumn{2}{|c|}{$<40$} & \multicolumn{2}{|c|}{$40-44$} & \multicolumn{2}{|c|}{$45-49$} & \multicolumn{2}{|c|}{ Total } \\
\hline & & & & M.I. Patients & Controls & M.I. Patients & Controls & M.I. Patients & Controls & M.I. Patients & Controls \\
\hline Never used & .. & .. & $\ldots$ & $18(38 \cdot 3)$ & $49(64 \cdot 5)$ & $42(80 \cdot 8)$ & $46(88 \cdot 5)$ & $44(95 \cdot 7)$ & $47(88 \cdot 7)$ & $104(71 \cdot 7)$ & $142(78 \cdot 5)$ \\
\hline $\begin{array}{l}\text { Current users } \\
\text { Ex-users }\end{array}$ & $\therefore$ & $\therefore$ & 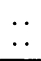 & $\begin{array}{rr}21 & (44 \cdot 7) \\
8 & (17 \cdot 0)\end{array}$ & $\begin{array}{ll}17 & (22 \cdot 4) \\
10 & (13 \cdot 2)\end{array}$ & $\begin{array}{lr}8 & (15 \cdot 4) \\
2 & (3.8) \\
\end{array}$ & $\begin{array}{ll}2 & (3 \cdot 8) \\
4 & (7 \cdot 7)\end{array}$ & $2(4 \cdot 3)$ & $6(11 \cdot 3)$ & $\begin{array}{lr}31 & (21.4) \\
10 & (6.9)\end{array}$ & $\begin{array}{ll}19(10 \cdot 5) \\
20(11 \cdot 1)\end{array}$ \\
\hline Users at any time & .. & . & .. & $29(61 \cdot 7)$ & $27(35.5)$ & $10(19 \cdot 2)$ & $6(11.5)$ & $2(4 \cdot 3)$ & $6(11 \cdot 3)$ & $41 \quad(28 \cdot 3)$ & $39(21 \cdot 5)$ \\
\hline Total & .. & . & . & $47(100 \cdot 0)$ & $76(100 \cdot 0)$ & $52(100 \cdot 0)$ & $52(100 \cdot 0)$ & $46(100 \cdot 0)$ & $53(100 \cdot 0)$ & $145(100 \cdot 0)$ & $181(100 \cdot 0)$ \\
\hline Not known & . & $\ldots$ & . & 4 & 5 & 2 & 4 & 2 & 6 & 8 & 15 \\
\hline $\begin{array}{l}\text { Comparison betwee } \\
\text { Relative-risk estima }\end{array}$ & & . & $\because$ & $x_{1}^{2}=5 \cdot 78 ;$ & $<P<0.02$ & $P=0.05($ Fis & 3 exact test) & & & $x_{1}^{2}=11 \cdot 19$ & $P<0.001$ \\
\hline
\end{tabular}

N.S. $=$ Not significant.

TABLE III-Total Duration of Use of Oral Contraceptives by Myocardial Infarction and Control Patients Who were Current Users. Percentages are Given in Parentheses

\begin{tabular}{|c|c|c|c|c|c|c|c|c|c|c|c|}
\hline \multirow{3}{*}{\multicolumn{4}{|c|}{ Total Duration of Use }} & \multicolumn{6}{|c|}{ Age Group of Women (Years) } & \multirow{2}{*}{\multicolumn{2}{|c|}{ Total* }} \\
\hline & & & & \multicolumn{2}{|c|}{$<40$} & \multicolumn{2}{|c|}{$40-44$} & \multicolumn{2}{|c|}{$45-49$} & & \\
\hline & & & & M.I. Patients & Controls & M.I. Patients & Controls & M.I. Patients & Controls & M.I. Patients & Controls \\
\hline $\begin{array}{l}\text { Up to } 3 \text { months } \\
4-12 \text { months } \quad . \\
13-24 \text { months } \\
25 \text { months or more }\end{array}$ & $\begin{array}{l}\ldots \\
\cdots \\
\cdots\end{array}$ & $\begin{array}{l}\cdots \\
\therefore \\
\cdots\end{array}$ & $\begin{array}{l}\cdots \\
\cdots \\
\cdots\end{array}$ & $\begin{array}{rr}2 & (10.0) \\
3 & (15.0) \\
2 & (10.0) \\
13 & (65.0) \\
\end{array}$ & $\begin{array}{ll}3 & (17 \cdot 6) \\
5 & (29 \cdot 4) \\
2 & (11 \cdot 8) \\
7 & (41 \cdot 2)\end{array}$ & $\begin{array}{ll}1 & (12.5) \\
1 & (12.5) \\
6 & (75.5) \\
\end{array}$ & $\begin{array}{ll}1 & (50 \cdot 0) \\
1 & (50 \cdot 0) \\
\end{array}$ & $2(100 \cdot 0)$ & & $\begin{array}{rr}2 & (6 \cdot 7) \\
4 & (13 \cdot 3) \\
3 & (10 \cdot 0) \\
21 & (70 \cdot 0) \\
\end{array}$ & $\begin{array}{ll}3 & (15 \cdot 8) \\
5 & (26 \cdot 3) \\
3 & (15 \cdot 8) \\
8 & (42 \cdot 1) \\
\end{array}$ \\
\hline Total & & & & $20(100 \cdot 0)^{*}$ & $17(100 \cdot 0)$ & $8(100 \cdot 0)$ & $2(100 \cdot 0)$ & $2(100 \cdot 0)$ & & $30(100 \cdot 0)$ & $19(100 \cdot 0)$ \\
\hline
\end{tabular}

*Duration of use was not known for one patient. 
TABLE IV-Treated Hypertension and Diabetes in Myocardial Infarction and Control Patients. Percentages are Given in Parentheses

\begin{tabular}{|c|c|c|c|c|c|c|c|c|}
\hline & \multicolumn{6}{|c|}{ Age Group of Women (Years) } & \multirow{2}{*}{\multicolumn{2}{|c|}{ Total }} \\
\hline & \multicolumn{2}{|c|}{$<40$} & \multicolumn{2}{|c|}{$40-44$} & \multicolumn{2}{|c|}{$45-49$} & & \\
\hline & M.I. Patients & Controls & M.I. Patients & Controls & M.I. Patients & Controls & M.I. Patients & Controls \\
\hline $\begin{array}{l}\text { No treatment. } \\
\text { Regular drug therapy for less than } 3 \\
\text { years } \\
\text { Regular drug therapy for more than } \\
3 \text { years } \\
\text { Intermittent therapy } . \\
\end{array}$ & $\begin{array}{rr}40 & (83 \cdot 3) \\
3 & (6 \cdot 3) \\
3 & (6 \cdot 3) \\
2 & (4 \cdot 2) \\
\end{array}$ & $81(100 \cdot 0)$ & $\begin{array}{rr}40 & (78 \cdot 4) \\
3 & (5 \cdot 9) \\
7 & (13 \cdot 7) \\
1 & (2 \cdot 0) \\
\end{array}$ & 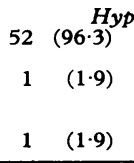 & $\begin{array}{rr}\text { ension } & \\
34 & (72 \cdot 3) \\
3 & (6 \cdot 4) \\
8 & (17 \cdot 0) \\
2 & (4 \cdot 3) \\
\end{array}$ & $\begin{array}{rr}53 & (93 \cdot 0) \\
3 & (5 \cdot 3) \\
1 & (1 \cdot 7)\end{array}$ & $\begin{array}{rr}114 & (78 \cdot 1) \\
9 & (6 \cdot 2) \\
18 & (12 \cdot 3) \\
5 & (3 \cdot 4) \\
\end{array}$ & $\begin{array}{rr}186 & (96 \cdot 9) \\
4 & (2 \cdot 1) \\
2 & (1 \cdot 0) \\
\end{array}$ \\
\hline Total & $48(100 \cdot 0)$ & $81(100 \cdot 0)$ & $51(100 \cdot 0)$ & $54(100 \cdot 0)$ & $47(100 \cdot 0)$ & $57(100 \cdot 0)$ & $146(100 \cdot 0)$ & $192(100 \cdot 0)$ \\
\hline Not known. & 3 & & 3 & 2 & 1 & 2 & 7 & 4 \\
\hline $\begin{array}{l}\text { M.I. patients } v \text {. controls irrespective } \\
\text { of duration of therapy* }{ }^{*} \quad \ldots\end{array}$ & $\mathbf{P}=\mathbf{c}$ & 002 & $P=$ & 005 & $\mathbf{P}=$ & 005 & $\chi_{1}^{2}=25.74 ;$ & $P<0.001$ \\
\hline $\begin{array}{lllll}\text { No treatment. } & \ldots & \ldots & \ldots \\
\text { Diet only } & \ldots & \ldots & \ldots & \ldots \\
\text { Oral hypoglycaemic } \\
\text { Insulin }\end{array}$ & $\begin{array}{cc}\frac{48}{2} & (94 \cdot 1) \\
2 & (3 \cdot 9) \\
1 & (2 \cdot 0) \\
\end{array}$ & $81(100 \cdot 0)$ & $\begin{array}{lr}\frac{49}{2} & (90 \cdot 7) \\
2 & (3 \cdot 7) \\
3 & (5 \cdot 6) \\
\end{array}$ & $\underline{56}^{(100 \cdot 0)^{D}}$ & $\begin{array}{rr}\text { etes } & \\
\frac{46}{1} & (95 \cdot 3) \\
1 & (2 \cdot 1) \\
1 & (2 \cdot 1)\end{array}$ & $\begin{array}{cc}58 & (98 \cdot 3) \\
1 & (1 \cdot 7)\end{array}$ & $\begin{array}{rr}143 & (93 \cdot 5) \\
5 & (3.3) \\
5 & (3.3)\end{array}$ & $\begin{array}{rr}195 & (99 \cdot 5) \\
1 & (0 \cdot 5) \\
\end{array}$ \\
\hline Total & $51(100 \cdot 0)$ & $81(100 \cdot 0)$ & $54(100 \cdot 0)$ & $56(100 \cdot 0)$ & $48(100 \cdot 0)$ & $59(100 \cdot 0)$ & $153(100 \cdot 0)$ & $196(100 \cdot 0)$ \\
\hline $\begin{array}{l}\text { M.I. patients } v \text {. controls irrespective } \\
\text { of type of therapy* }\end{array}$ & & & $\mathbf{P}=$ & 02 & & & & .002 \\
\hline
\end{tabular}

*P derived by Fisher's exact test.

which occurred in $1966 .{ }^{1}$ Since then the use of oral contraceptives has increased almost threefold. ${ }^{7}$ This observation, together with the fact that the dead patients in this study appeared to have been using oral contraceptives for longer than the control patients who were current users, may help to explain the more positive findings of this study. In 1966, oral contraceptives had been in widespread use for only five years.

No significant difference in the use of high-dose oestrogen preparations was found between patients with infarction and controls who had been using oral contraceptives before 1970 . This is, perhaps, surprising in view of the positive correlation between oestrogen dose and the risk of myocardial infarction found in a study of suspected adverse reactions to oral contraceptives reported to the Committee on Safety of Drugs, ${ }^{3}$ but failure to establish a clear relationship between oestrogen doses and other thromboembolic complications has been a feature of other studies which (like this one) were based on relatively small numbers. ${ }^{18}$ When the results of three studies published in 1968 and 1969 were combined, however, an excess of cases of thromboembolism was apparent in women taking oral contraceptives containing $150 \mu \mathrm{g}$ oestrogen. ${ }^{3}$

The possible sources of bias which might have influenced the relationships observed in this study include the fact that 58 $(21 \%)$ of the 277 deaths selected for study could not be investigated because the general practitioner was not traced or was unable to collaborate. It seems unlikely, however, that bias could have been introduced for this reason because control patients were selected only from the practice lists of co-operating doctors. Another possible source is that there must have been some deaths due to myocardial infarction in the relevant sex and age groups of which we were not notified because of incorrect death certification or administrative difficulties. Indeed, we are aware of two such deaths-one which occurred in a woman using an oral contraceptive, which was notified as an adverse reaction to the Committee on Safety of Medicines, and another in a patient with longstanding diabetes. (These two cases were not, of course, included in our analysis.) Only five of the 31 deaths in women using oral contraceptives at the time of death were, however, reported to the Committee on Safety of Medicines, and this finding together with the fact that deaths were included only when the diagnosis was confirmed at necropsy or substantiated by unequivocal clinical and laboratory findings make the possibility that myocardial infarction was simply diagnosed more often in oral contraceptive users extremely unlikely. It is, furthermore, interesting that the frequency of oral contraceptive use was the same in patients with infarction whose cause of death was confirmed at necropsy as in those in whom the diagnosis depended on clinical and laboratory findings.
Of great importance is the fact that the control population should be representative of the general population of women of childbearing age with regard to their oral contraceptive practice. Comparison with a recent national survey, however, suggests that the current oral contraceptive use in our control population under 40 years of age was greater than might have been expected, 910 and this, if true, would have tended to reduce the association found between myocardial infarction and oral contraceptive use. A possible explanation might be an "overmatching" phenomenon if general practitioners had tended to be either regular oral contraceptive prescribers or not. An association between myocardial infarction and oral contraceptive use would then have lead the investigator, when following up deaths from infarction, to practices where the prescribing of these drugs was more frequent, and hence the control population selected from these practices would tend to include more users than the general population of the same age group.

The procedure adopted here certainly resulted in more intensive investigation of the patients with infarction than of the control women, in that information concerning the dead patients was also sought from hospital case notes, family planning clinic records, necropsy reports, and court records. It may therefore be considered that information on oral contraceptive use was more likely to be obtained for these patients than for the living controls. Of the 41 patients found to have been using oral contraceptives, however, 39 had this information recorded in their general practitioners' records, which provided the primary source of information for both the patients with myocardial infarction and the controls.

An investigation of this type can provide little evidence of the mechanism by which oral contraceptives give rise to a risk of myocardial infarction. The fact that the patients with infarction had been using them longer on average than the control patients may suggest that their use contributes to the atherogenic processes. It must be noted, however, that current use of oral contraceptives was more important than use at some time in the past. Moreover, $83 \%$ of the necropsy reports on women who had been using oral contraceptives at the time of death mentioned a thrombus in the coronary arteries, whereas only $55 \%$ of the reports on patients who had not been using the preparations mentioned this finding. This difference is significant at the $5 \%$ level. The latter finding should be interpreted with great caution, since the techniques for examining these arteries are critical and could clearly not be controlled in any way in a study of this kind. These two observations, however, weigh in favour of the hypothesis that a thrombotic tendency rather than increased atheroma explains, at least to some extent, the increased risk attributed to the use of these drugs. 
The data derived from this study and information on the structure of the female population of England and Wales derived from the Registrar General's report make it possible to estimate the mortality from myocardial infarction in women who use oral contraceptives and in those who do not. In the 30-39-year age group the yearly death rate in women not using these preparations is estimated to be 1.9 per 100000 compared with 5.4 per 100000 in women who are using them. In the 40-44-year age group the yearly death rates are 11.7 and 54.7 per 100000 respectively.* It seems, then, that the risk of death from myocardial infarction was increased about 2.8 times in current users of oral contraceptives aged 30-39 years and about 4.7 times in women aged 40-44 years.

In absolute terms the attributable mortality was considerably lower in women aged 30-39 years than in those aged 40-44 years, there being an excess of 3.5 deaths per 100000 users yearly in the former group and 43 per 100000 users yearly in the latter group. These estimates of risk are similar to the increased risk of non-fatal infarction estimated by Mann et al. ${ }^{11}$ but still need to be interpreted with caution, as a number of assumptions have necessarily had to be made in their calculation and the margin of error is likely to be fairly wide. We do, nevertheless, consider them to be helpful in providing a crude estimate of risk of death from myocardial infarction in women currently using oral contraceptives.

* These data are too few to justify making estimates for women aged 45-49 years, in whom the yearly mortality rate in 1973 (in users and non-users combined) was $29 \cdot 4$ per 100000 .
We are grateful to the medical officers on the committee's staff who carried out the interviews, to the many doctors who gave their time to provide us with information, and to Sir Richard Doll and Professor M. P. Vessey for advice and encouragement. Dr. A. M. Adelstein and Mr. J. G. Gerrard, of the Office of Population Censuses and Surveys, kindly arranged for us to receive the transcripts of death certificates. Miss A. Renauld, Mrs. M. Spellman, and Mrs. G. Mead provided invaluable secretarial help, and Mrs. M. Thorogood and Mr. R. Golding and his staff, of the Oxford Regional Health Authority, helped with the analysis of the results. J.M. was supported by an I.C.I. Fellowship and by the Cecil John Adams Memorial Fellowship during the period of this study. We are grateful to Sir Eric Scowen and the Committee on Safety of Medicines for permission to report these data.

Requests for reprints should be addressed to: Dr. W. H. W. Inman, Committee on Safety of Medicines, Finsbury Square House, 33/37A Finsbury Square, London EC2A 1PP.

\section{References}

1 Inman, W. H. W., and Vessey, M. P., British Medical fournal, 1968, 2, 193. 2 Vessey, M. P., and Doll, R., British Medical fournal, 1969, 2, 651.

3 Inman, W. H. W., et al., British Medical fournal, 1970, 2, 203.

4 World Health Organization, Working Group on Ischaemic Heart Disease Registers. W.H.O., Regional Office for Europe, Copenhagen, 1971

${ }^{5}$ Miettinen, O. S, Biometrics, 1970, 26, 75 .

- Armitage, P., Statistical Methods in Medical Research, p. 363. Oxford, Blackwell Şcientific, 1971.

7 Vessey, M. P., and Inman, W. H. W., fournal of Obstetrics and Gynaecology of the British Commonwealth, 1973, 80, 562.

8 Vessey, M. P., and Doll, R., British Medical fournal, 1968, 2, 199.

$\checkmark$ Bone, M. Family Planning Services in England and Wales. London, H.M.S.O., 1973 .

${ }^{10}$ Bone, M., personal communication, 1973.

11 Mann, J. I., et al., British Medical fournal, 1975, 2, 245.

\title{
Maintenance of Labour
}

\author{
J. M. BEAZLEY, I. BANOVIC, M. S. FELD
}

British Medical fournal, 1975, 2, 248-250

\section{Summary}

In 160 women large but variable amounts of intravenous oxytocin were needed to induce labour within a reasonable time interval to $5 \mathrm{~cm}$ cervical dilatation. Thereafter $7 \mathrm{mU}$ of oxytocin/min would maintain progress. Since larger maintenance doses may cause obstetric problems it is recommended that a maintenance regimen should be used once labour has progressed to this stage.

\section{Introduction}

Induction-delivery intervals much over 12 hours are no longer acceptable. Small quantities of oxytocin (Syntocinon) infused intravenously for prolonged periods induce labour in many women who are near term. To ensure induction in all patients within a reasonable time, however, methods such as oxytocin titration $^{1}$ and an increasing rate of infusion have been developed.

\footnotetext{
University Department of Obstetrics and Gynaecology, Liverpool L69 3BX

Little attention has been paid to the maintenance of labour after such regimen. We have studied the modern process of labour stimulation to see whether a stage is reached beyond which oxytocin requirements are greatly reduced.

\section{Patients and Methods}

Labour was induced in 83 multiparous and 77 primiparous women between 266 and 294 days of gestation. The indications for induction are shown in table I. All the fetuses presented cephalically. Except for women excluded because of possible cephalopelvic disproportion consecutive patients were treated.

TABLE I-Indications for Induction of Labour

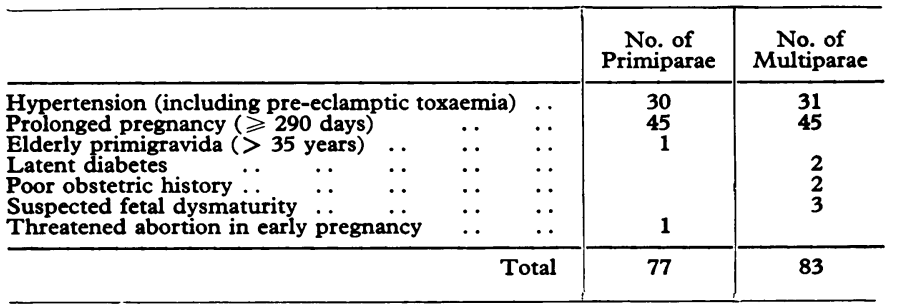

Intravenous oxytocin infusion was started immediately after low amniotomy in all patients. At the time of amniotomy the Bishop score was estimated according to the criteria in table II. The dose regimen used for increasing oxytocin is shown in table III. After starting 